\title{
Dialysis or death? Doctors should stop covering up for an inadequate health service
}

\author{
E D Ward British Kidney Patient Association
}

\section{Author's abstract}

Doctors who entered the National Health Service to practise medicine now find themselves forced to practise selection. It seems that patients are being lost at GP level.

Surely the basis of a good relationship between doctor and patient relies on trust and trust is based on truth which should not be concealed from patients. And should any one dare decide the quality of life for another human being?

The Renal Replacement Programme in Great Britain, which is the responsibility of the National Health Service (NHS), is severely underfunded and as a result patients are dying in our country, not because treatment is unknown but because no treatment is being made available for them. Whilst there are differing views on the number of renal patients who die untreated in this country, it would be fair to say that some two thousand patients are currently living under sentence of death. There are sixty-three renal units serving a population of nearly sixty million people spread unevenly throughout the country; seven more are devoted to the treatment of children with renal failure. The needs of the patients destined for transplantation are covered by no more than thirty transplant teams operating from the adult units and of these only sixteen per cent employ a full-time transplant surgeon. Great Britain was one of the first European countries to undertake chronic haemodialysis as early as 1961; in those proud days there were adequate facilities to cope with the number of patients requiring treatment. But as those numbers increased and the facilities to treat them remained virtually the same, we found ourselves falling rapidly to the bottom of the list of countries in the Western world in this respect, offering treatment to fewer per capita of the population than any other Western European country bar one.

I came on the scene as the mother of a young kidney patient some nineteen years ago, when the words 'dialysis' and 'transplantation' were virtually unspoken except amongst the medical profession, and developed into a crusader in 1971. Since that time the only thing that has significantly increased I think has been the

\section{Key words}

Dialysis; British NHS; patient selection; inadequate funding; BKPA; allocation of scarce resources. number of patients requiring treatment and, I suppose, my knowledge.

Doctors who entered the health service to practise medicine now find themselves forced to practise selection. Surely the only ethical reason for the denial of treatment to a patient requiring dialysis is his or her own refusal of treatment or some medical consideration making treatment impossible; but in our country patients are being turned away to die for reasons unconnected with their medical condition, such as social background, language barriers, or the inability - in the opinion of the physicians - to cope with a kidney machine at home. Doctors are even daring to decide on the quality of life for their patients when no one in my opinion has the right to decide on the quality of life for another human being unless that human being is mentally or physically incapable of making that decision for him or herself.

Patients with spina bifida, diabetes, paraplegia for example, or even a past history of cancer or mental disorder who have been treated and taken care of by the health service since the onset of their medical condition find themselves suddenly sentenced to death because renal failure has developed and they are considered unsuitable for further treatment. Some of these fearful decisions would not be made were there adequate facilities to treat all renal patients requiring dialysis.

A young American doctor who was researching the problem caused by lack of facilities and, therefore, treatment, for British kidney patients in end-stage renal failure, came to see me at my office some weeks ago. Whisper had carried across the Atlantic that British kidney patients were being sentenced to death and he had $\%$ been sent over here to establish the truth for himself. $\mathrm{He}$ returned to his country carrying our shame, to write an article for a widely read medical publication proclaiming the news that indeed it was true that hundreds of kidney patients of retirement age were destined never to reap the benefit of their savings, have an opportunity of indulging in their hobbies or know the luxury of true leisure $\mathbb{D}$ because the British NHS was underfunded and, therefore, they were being denied treatment and were dying as a result.

Before he returned to his own country he called in at my office on a flying visit and told me that after visiting no fewer than eleven renal units he had not found one 
consultant prepared to admit that he was having to practise selection because the resources were insufficient for him to offer treatment to all the patients who required it. They knew that this problem did occur in Britain he said, "shaming" some of them said it was "but not in this unit, we are fortunate" '. The same old story is trotted out to everyone. The concealment of the true facts from not only the press but even the relatives and the patients themselves is probably the greatest cause of the present problem.

What is the explanation for this? It is my belief that the unfortunate doctors who are having to advise or practise selection, because they have no choice, are forced to rationalise their actions in order that they may live peacefully within themselves, go home and eat their supper and sleep at night. They have got so used to justifying their decisions that they are able to make quite horrifying statements sound mundane.

I was talking to a renal consultant of a large London unit quite recently and asked him how he was coping with the shortage of facilities? 'Are you having to practise selection yourself still?' I asked. 'No' he replied 'actually we have been very lucky and recently have only had to turn down one or two impossibles and, of course, a sikh'. I was discussing the old problem with a young consultant at another London unit who was a compassionate, caring man, who was obviously distressed at finding himself in a position where he was not able to offer treatment to all his patients who required it. 'What would you do if you were me?' he asked. 'I am funded for twenty-seven slots, what would you say to the twenty-eighth patient?'-I told him that I would tell the patient and his relatives the true situation and I would put in writing to the Chairman of his Regional Health Authority and the Secretary of State the fact that a patient had been referred to him who would in a matter of weeks require dialysis but that since he already had his quota of patients he was not going to be in a position to treat him when the time came. 'Why' I asked him 'should you shoulder the responsibility for the death of this patient when the responsibility clearly is not yours?'

I would like to be able to tell you that a whole new system is now operating at that particular renal unit but alas I cannot since that is not the case. Many of the renal physicians will say that they are aware that there are patients slipping through the net but that these patients are being lost at general practitioner level, but a recent Gallup questionnaire commissioned by the British Kidney Patient Association (BKPA) showed that this was not the case. If it were the case what are the renal consultants doing about it? Surely they are not standing back allowing these patients to die untreated and merely congratulating themselves that they are not the guilty ones.

To change the subject slightly, a general physician of long-standing recently shared this problem with me and asked my opinion. One of his regular visits was to a terminal cancer patient who persistently asked him when she could expect to get better. He had confided the seriousness of his patient's illness to her husband who had begged him to keep the true facts to himself. He felt uncomfortable in the presence of his patient and dreaded his weekly visits. What would I do he asked.

My immediate reaction was that he should, of course, tell his patient the truth and I wondered why he had withheld it in the first place. In entering into a conspiracy with the husband, he had put himself quite unnecessarily into a most unenviable position, broken trust with the very person whose trust he enjoyed and furthermore had presumed that the husband was right in thinking that his wife would wish the knowledge of her impending death to be withheld from her. It might well have been that the wife would have chosen to withhold the truth from her husband but she was denied that choice.

Surely the basis of a good relationship between doctor and patient relies on trust and trust is based on truth. The joy of truth is that it is so simple, so black and white. No longer need the doctor concern himself with whether or not his patient is emotionally or physically strong enough to stand the truth. The patient need no longer anxiously study the doctor's face trying to decide whether or not the truth is being spoken.

The truth can be told with imagination and compassion, prefaced with the words 'in my opinion' thus leaving a ray of hope for those who cannot face it. I have a file in my office shamefully thick, with letters from patients and those that love them filled with a mixture of anguish and abuse, worry and heartache which would never have been written if the writers had been sure that the truth had been told them.

I am at the moment heavily involved with a number of tragic cases concerning the deaths of renal patients in unfortunate circumstances whose relatives are now seeking retribution. My task, as I see it, is to allay the fears, soften the criticism and help these unfortunate people to come to terms with their loss in the belief that death was inevitable. I know the truth, no matter how unpalatable, would have been found acceptable and their wounds would have healed over, leaving no scars, but now whilst the dead rest in peace those left behind are restlessly seeking the truth.

I cannot understand why renal physicians in this country feel it necessary to cover up for an inadequate health service and pull the wool over the eyes of relatives and patients by telling them dialysis treatment could not solve the problem or save the patient's life when they know that the truth is that it would. The patient has the right to know that in an ideal world he would, of course, receive dialysis treatment even if no promises could be made as to how long the treatment would prolong his life.

I will give you an example of what I mean. Some time ago a renal consultant of note told me, in illustrating the problems he was facing with a shortage of facilities, that two patients in his clinic had arrived at the same point at precisely the same time and both of them were in need of dialysis in the same week. He only had facilities for one patient and decided to make those facilities available to a thirty-four-year-old mother of two in favour of a seventeen-year-old girl. The girl had, of course, naturally died and when I protested and told him that had I known 
I might have been able to arrange for her to receive treatment in one of the London units his reply was 'But these were ordinary working-class people who had lived all their lives in Hawkesworth. Why would they want to come to London?' Are not working-class people allowed to love their children to the point of doing all in their power to save their lives, even if it does mean uprooting themselves?

Whether the patient be a sixty-four-year-old diabetic or a thirty-one-year-old paraplegic, is he to be denied the truth as well as being denied the treatment? Much has been written about the quality of life but as I have already said no one has the right to make judgement on the quality of life for another human being; only that human being himself can decide whether or not the quality of his own life is worth his struggle for existence.

Renal physicians take too much upon themselves and so have now become accustomed to making decisions concerning the future of their patients as to whether indeed they will have a future at all, without even consultation with the close relatives of the patient, let alone the patient himself.

I have looked quite closely into three other areas of medicine where life/death decisions could be made by physicians, but on the whole are not. Patients with cerebral palsy, spinal injuries and terminal cancer are ministered to by doctors who tell me they would seldom consider not treating initially and would only withdraw treatment after consultation with the relatives and where possible with the patients themselves.

The 'quality of life' is never given as a reason for not treating, despite the fact that to the onlooker the quality of life of all these patients is far less enviable than that of the patient on renal dialysis. What then can be the reason that the attitudes and behaviour of the physicians looking after renal patients differ so greatly from those caring for $\stackrel{\frac{m}{5}}{\overrightarrow{0}}$ patients in other fields of medicine? I accept that the shortage of facilities for the treatment of patients with end-stage renal failure forces the renal physician to $\stackrel{?}{?}$ practise selection. He lives in an isolated medical world, cut off from his colleagues except at table, destined to treat the same patients year after year until their death.

$\mathrm{He}$ is quite rightly proud of the kingdom he rules, $\unrhd$

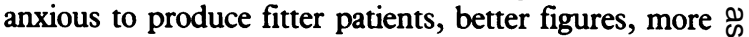
transplants than his competitors and takes as a personal failure his inability to treat all patients who are referred to him in need of treatment. Perhaps that is why he feels it $\bar{\omega}$ necessary to hide the truth and give reasons for the denial of treatment based on his own judgement and not on the lack of facilities, which is outside his control.

No blame can be attached to the doctor unable to offer life-saving treatment to his patient because of lack of $\sigma o$ facilities but can he not be blamed for concealing the truth, not only from the patient and those that love him but also from those agencies both eager and able to help? And can he not be blamed for his continual acceptance of the present situation?

If we are ever to see the day when the only criterion for treatment is the need for it, then the doctors must stand up as one man and in a loud voice proclaim 'We cannot practise medicine under these conditions and furthermore we will not'.

This paper was first given under the auspices of the London Medical Group to a meeting at Charing Cross Hospital.

Mrs Elizabeth Despard Ward, MBE, is President of the British Kidney Patient Association, Bordon, Hants, and author of Timbo - A struggle for Survival, published by Sidgwick and Fackson. 